\title{
Generalization on the Basis of Prior Experience Is Predicted by Individual Differences in Working Memory
}

Citation for published version (APA):

Lenaert, B., van de Ven, V., Kaas, A. L., \& Vlaeyen, J. W. S. (2016). Generalization on the Basis of Prior Experience Is Predicted by Individual Differences in Working Memory. Behavior Therapy, 47(1), $130-140$. https://doi.org/10.1016/j.beth.2015.10.001

Document status and date:

Published: 01/01/2016

DOI:

10.1016/j.beth.2015.10.001

Document Version:

Publisher's PDF, also known as Version of record

Document license:

Taverne

Please check the document version of this publication:

- A submitted manuscript is the version of the article upon submission and before peer-review. There can be important differences between the submitted version and the official published version of record.

People interested in the research are advised to contact the author for the final version of the publication, or visit the DOI to the publisher's website.

- The final author version and the galley proof are versions of the publication after peer review.

- The final published version features the final layout of the paper including the volume, issue and page numbers.

Link to publication

\footnotetext{
General rights rights.

- You may freely distribute the URL identifying the publication in the public portal. please follow below link for the End User Agreement:

www.umlib.nl/taverne-license

Take down policy

If you believe that this document breaches copyright please contact us at:

repository@maastrichtuniversity.nl

providing details and we will investigate your claim.
}

Copyright and moral rights for the publications made accessible in the public portal are retained by the authors and/or other copyright owners and it is a condition of accessing publications that users recognise and abide by the legal requirements associated with these

- Users may download and print one copy of any publication from the public portal for the purpose of private study or research.

- You may not further distribute the material or use it for any profit-making activity or commercial gain

If the publication is distributed under the terms of Article $25 \mathrm{fa}$ of the Dutch Copyright Act, indicated by the "Taverne" license above, 


\title{
Generalization on the Basis of Prior Experience Is Predicted by Individual Differences in Working Memory
}

\author{
Bert Lenaert ${ }^{1}$ \\ University of Leuven \\ Vincent van de Ven ${ }^{1}$ \\ Amanda L. Kaas \\ Maastricht University \\ Johan W.S. Vlaeyen \\ University of Leuven \\ Maastricht University
}

Generalization on the basis of prior experience is a central feature of human and nonhuman behavior, and anomalies in generalization can give rise to a wide array of problems. For instance, elevated levels of generalization have been shown in individuals suffering from an anxiety disorder. Identifying the individual difference variables that influence the extent to which behavior generalizes to novel stimuli may help our understanding of generalization and its potential maladaptive consequences. In this study, we first present an index of generalization that captures individual differences in generalization in a single continuous measure, thereby surpassing problems associated with traditional analyzing techniques. Further, we investigate whether generalization is predicted by working memory capacity. More precisely, it is hypothesized that generalization is a function of individual differences in the capacity to compare

\footnotetext{
${ }^{1}$ Equal contribution.

The authors thank L. Kerpershoek and L. Tielens for their assistance in collecting the data, and Yannick Boddez for his valuable comments during the writing process.

This research was supported by the Center of Excellence on Generalization Research (GRIP×TT; University of Leuven grant PF/ 10/005). Bert Lenaert is a research assistant for the FWO-Flanders.

Address correspondence to Bert Lenaert, Centre for the Psychology of Learning and Experimental Psychopathology, Faculty of Psychology and Educational Sciences, University of Leuven, Tiensestraat 102 - Bus 3712, 3000 Leuven, Belgium; e-mails: bert.lenaert@ppw.kuleuven.be; bert.lenaert@gmail.com. 0005-7894/@ 2015 Association for Behavioral and Cognitive Therapies. Published by Elsevier Ltd. All rights reserved.
}

the current situation with previous learning experiences in working memory, and to adjust subsequent behavior accordingly. In a community sample, we found higher levels of generalization in individuals who were less efficient at filtering out irrelevant information from access to working memory. These results suggest that working memory impairments may contribute to elevated and potentially maladaptive levels of generalization.

Keywords: generalization; generalization index; individual differences; working memory

GENERALIZATION ON THE BASIS OF PRIOR EXPERIENCE is a central feature of human and nonhuman behavior. It refers to the observation that learning about one stimulus or situation typically results in a tendency to respond to similar stimuli or situations in a similar way. For instance, feeling nauseated after eating a food item well past the expiration date may fuel the avoidance of other gone off food items in the future. Likewise, becoming a victim of a robbery in a dark alley may lead the victim to circumvent other alleys in different places.

Although this behavior is usually highly adaptive, anomalies in generalization can give rise to a wide array of problems. A failure to generalize after an aversive experience can result in recurring aversive experiences in the future (e.g., when eating another spoiled food item). In contrast, generalization 
can also become detrimental when it occurs too excessively. If a robbery victim starts avoiding not only other dark alleys, but all public places, daily functioning in social and professional contexts is compromised. In support of the importance of generalization, a growing amount of research highlights its involvement in a number of psychological and health problems. More precisely, elevated levels of generalization have been demonstrated in individuals suffering from anxiety disorders, including panic disorder, generalized anxiety disorder, and posttraumatic stress disorder (Lissek et al., 2010; Lissek et al., 2014; Lissek \& Grillon, 2012), as well as in patients with chronic pain disorder (Meulders, Jans, \& Vlaeyen, 2015).

The present study has a twofold aim. First, we will present an index that captures individual differences in generalization in a single continuous measure. Second, understanding generalization and its potential maladaptive consequences requires the identification of individual difference variables that influence the extent to which behavior expands to novel stimuli and situations. In this study, we will investigate whether generalization is associated with working memory in a community sample.

The first aim of this study, presenting an index of generalization, stems from a methodological problem associated with research on generalization. In most generalization studies, generalization is assessed by measuring responses to a set of test stimuli (GSs) and data are represented in the form of a response or generalization gradient (Ghirlanda \& Enquist, 2003). Generalization gradients allow quick visual inspection of the data pattern, but they do not provide a quantitative index that expresses the extent of generalization over repeated measurements. As a consequence, statistical analyses in generalization studies have traditionally been limited to analysis of variance (ANOVA) for repeated measures. However, this analysis strategy comes with several limitations (Vanbrabant et al., 2015). For instance, if the extent of generalization is the dependent variable and the variable of interest is continuous in nature (e.g., working memory capacity), repeated measures ANOVA requires creating categorical factors and subsequently comparing groups (e.g., by differentiating individuals high and low in working memory capacity based on a median-split procedure), which can create bias and omits a sizable amount of the variance present in the data (Taylor \& Yu, 2002). Although solutions to this problem have recently been proposed (i.e., multilevel analysis; Gazendam et al., 2014; Vanbrabant et al., 2015), we present another, straightforward way of dealing with the repeated nature of generalization data by deriving a single-a priori chosen-quantitative summary measure of generalization. Borrowing from older studies on generalization (for a review, see Honig \& Urcuioli, 1981) and the domain of endocrinological research that deals with repeated data as well (e.g., repeated measurements of cortisol levels throughout the day; Fekedulegn et al., 2007; Pruesnner, Kirschbaum, Meinlschmid, \& Hellhammer, 2003), we propose an index that takes into account responding to all generalization stimuli. In short, we will discuss the area under the curve, correcting for response strength to the $S+$. Importantly, this index will allow us and other researchers to investigate generalization in relation to other variables of interest in a continuous manner, thereby surpassing the problems associated with traditional analyzing techniques.

The second aim of this study is to investigate generalization in relation to working memory capacity. Working memory refers to a limited capacity system that provides the temporary storage and manipulation of information that is necessary for performing a wide range of complex tasks (Baddeley, 2012). In recent years, the role of working memory and other cognitive processes has been a topic of debate in the literature on learning and conditioning. A central question is whether the learning of associations between events requires some degree of cognitive processing or rather occurs unconsciously and automatically (Mitchell, De Houwer, \& Lovibond, 2009). This has also been discussed in relation to generalization specifically, in that discrimination and generalization may be based-in part—on inductive reasoning judgments and the derivation of rules from episodic or working memory (Livesey \& McLaren, 2009). Further, experimental evidence indicates that installing a dual task load that overburdens working memory capacity affects several learning phenomena, such as extinction learning (Raes, De Raedt, Verschuere, De Houwer, 2009), blocking (De Houwer \& Beckers, 2003), and generalization in a patterning task (Wills, Graham, Koh, McLAren, \& Rolland, 2011). Up to this point, however, it remains unclear whether preexisting individual differences in working memory capacity are associated with generalization. Here, it is hypothesized that the extent of generalization is a function of individual differences in the capacity to compare the current situation with previous learning experiences retrieved from memory, and to adjust subsequent behavior accordingly (e.g., engage or inhibit a previously learned response). If working memory capacity is limited, there are less opportunities for storage of relevant stimulus features, leading to less discrimination between stimuli and, hence, more generalization. We predict 
that individuals characterized by a limited capacity to retain and process information in working memory will show higher levels of generalization.

It is well known that working memory capacity to retain items actively in mind is limited to only a relatively small number of items (Baddeley, 2012; Cowan, 2001). Increasing the number of to-be remembered items results in impaired subsequent recognition or recall of memorized items. Thus, successful retention of items in a capacity-limited system requires that irrelevant information is prevented from entering working memory and occupying resources. It has been shown that individuals differ in their efficiency in inhibiting or filtering irrelevant information from working memory (Kane \& Engle, 2003; Vogel, McCollough, \& Machizawa, 2005; Zanto \& Gazzaley, 2009), which in turn may affect working memory capacity and the successful retention of relevant information in memory.

In the present study, generalization is investigated in a contingency learning procedure. Human contingency learning procedures are an often used and thoroughly explored method for examining learning phenomena (De Houwer \& Beckers, 2002). With respect to generalization specifically, the contingency learning task we used has previously evidenced the capacity to elicit generalization in humans and to reveal individual differences in generalization as a function of (long-term autobiographical) memory (Lenaert et al., 2012). In this task, one picture of a female face $\left(S_{+}\right)$is followed by a neutral outcome, whereas another picture of a female face (S-) is never followed by the outcome, and participants are requested to identify the predictive relations between the pictures and the outcome. Subsequently, generalization is assessed by presenting a number of pictures (generalization stimuli, GS) sharing features of both the $S+$ and the $S$ - to a greater or lesser extent. Specialized face morphing software was used to create a continuum of perceptual similarity between the $S+$ and the S-. Generalization occurs when these GSs elicit a learned response, although they were never paired with the outcome before. To investigate whether individual differences in working memory are associated with generalization, we employed a visuospatial working memory (VSWM) task that has been used in various forms in previous studies (Vogel, Woodman, \& Luck, 2001; Vogel et al., 2005). In this change detection task, a number of target items (e.g., squares) are presented for a brief period of time along with a number of distracter items (e.g., rectangles) that are to be ignored. At test, a single target item is presented and participants have to indicate whether any change occurred (e.g., in color, location, or orientation). Task performance has shown to be a direct function of the number of presented target and distracter items, but also varies substantially across individuals. For instance, individuals differ both in the number of items that they can correctly retain in memory, as well as in their efficiency at keeping irrelevant information (i.e., distracter items) from being stored in memory (i.e., "filtering cost"; Spronk, Vogel, \& Jonkman, 2012; Vogel et al., 2005). In support of the validity of the VSWM task, research using this task has evidenced a direct relationship between working memory capacity and neural activity (measured by recording event-related potentials; Vogel \& Machizawa, 2004), and has revealed performance deficits in adolescents relative to adults, demonstrating the capacity of this task to identify developmental differences in working memory (Spronk et al., 2012).

In sum, in the present study we present an index of generalization to quantify individual differences in generalization in a single continuous measure. Further, we aim to investigate whether individual differences in working memory capacity predict generalization based on prior experience. Given the adaptive function of generalization, and its potentially negative consequences, identifying the variables that can influence generalization may improve our understanding of this elementary learning phenomenon.

\section{PARTICIPANTS}

\section{Method}

We recruited 25 participants (16 females) from the community. Their mean age was $25.6(S D=9.7)$, and 21 participants were right-handed. Participation was awarded by financial compensation of 10 Euro. All participants gave written informed consent before participating in the study. The study was approved by the local Ethical Committee of the Faculty of Psychology and Neuroscience, Maastricht University (Netherlands).

\section{MATERIALS}

Visual stimuli of the experiments were shown on a laptop-controlled (running Windows 7 operating system) computer screen (refresh rate $=60 \mathrm{~Hz}, 34^{\circ} \mathrm{x}$ $27^{\circ}$ visual angle), which participants viewed at a distance of approximately $57 \mathrm{~cm}$. In the contingency learning task that included a generalization test, stimuli were presented on a black background in the center of the computer screen $(43.2 \mathrm{~cm})$. The task was programmed with Affect 4.0 software (Spruyt, Clarysse, Vansteenwegen, Baeyens, \& Hermans, 2010). The S+ and S- were pictures of neutral human female faces (DeBruine, 2005). For half of the participants, one picture of a female face served as $\mathrm{S}_{+}$, whereas the other picture served as S-. For the 


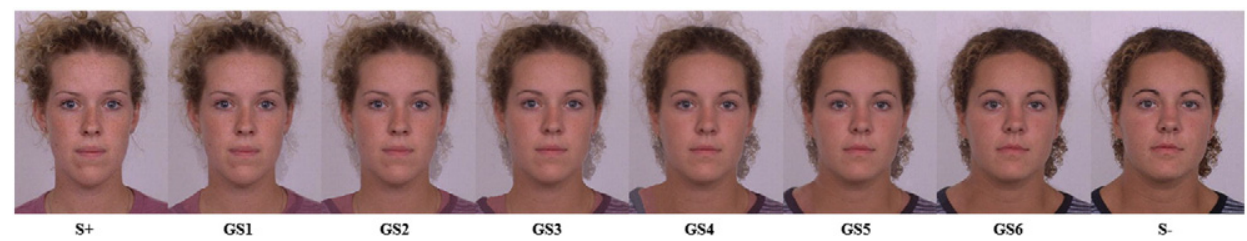

FIGURE I The S+, the S-, and the 6 generalization stimuli (GS) of the contingency learning task. For half of participants, the $\mathrm{S}+$, the $\mathrm{S}$ - and the corresponding GSs were reversed.

other participants, this was reversed. The pictures spanned appr. $9.5^{\circ}$ wide and $12.7^{\circ}$ high. The generalization stimuli were obtained by transforming the $S+$ into the $S$ - in six gradual steps using specialized software, resulting in six generalization stimuli that resembled the $S+(S-)$ to a greater or lesser extent (Figure 1). A drawing of a white lightning bolt, which measured $4.5^{\circ}$ by $2.8^{\circ}$, served as the outcome. The experimental trials consisted of the presentation of a picture of a female face $(S+, S-$ or GS), which was immediately followed by the outcome only after $\mathrm{S}+$ presentations (Figure 2). The lightning bolt was presented for $1500 \mathrm{~ms}$. The intertrial interval was set to $3000 \mathrm{~ms}$.
In the VSWM task, colored squares $\left(0.65^{\circ} \mathrm{x}\right.$ $\left.0.65^{\circ}\right)$ or rectangles $\left(0.5^{\circ} \times 1.65^{\circ}\right)$ were presented on both the right and the left half of the computer screen within a square region of $24^{\circ}$ centered on a fixation cross (after Vogel \& Machizawa, 2005; Spronk et al., 2012). This task was programmed in EventIDE (www.okazolab.com). On each trial, the positions of the items were randomly distributed within upper and lower quadrants of the screen with the constraint that the items could not touch or overlap. The color of the squares and rectangles varied randomly across trials between seven colors (red, green, blue, yellow, purple, black, white). All stimuli were presented on a grey background. There

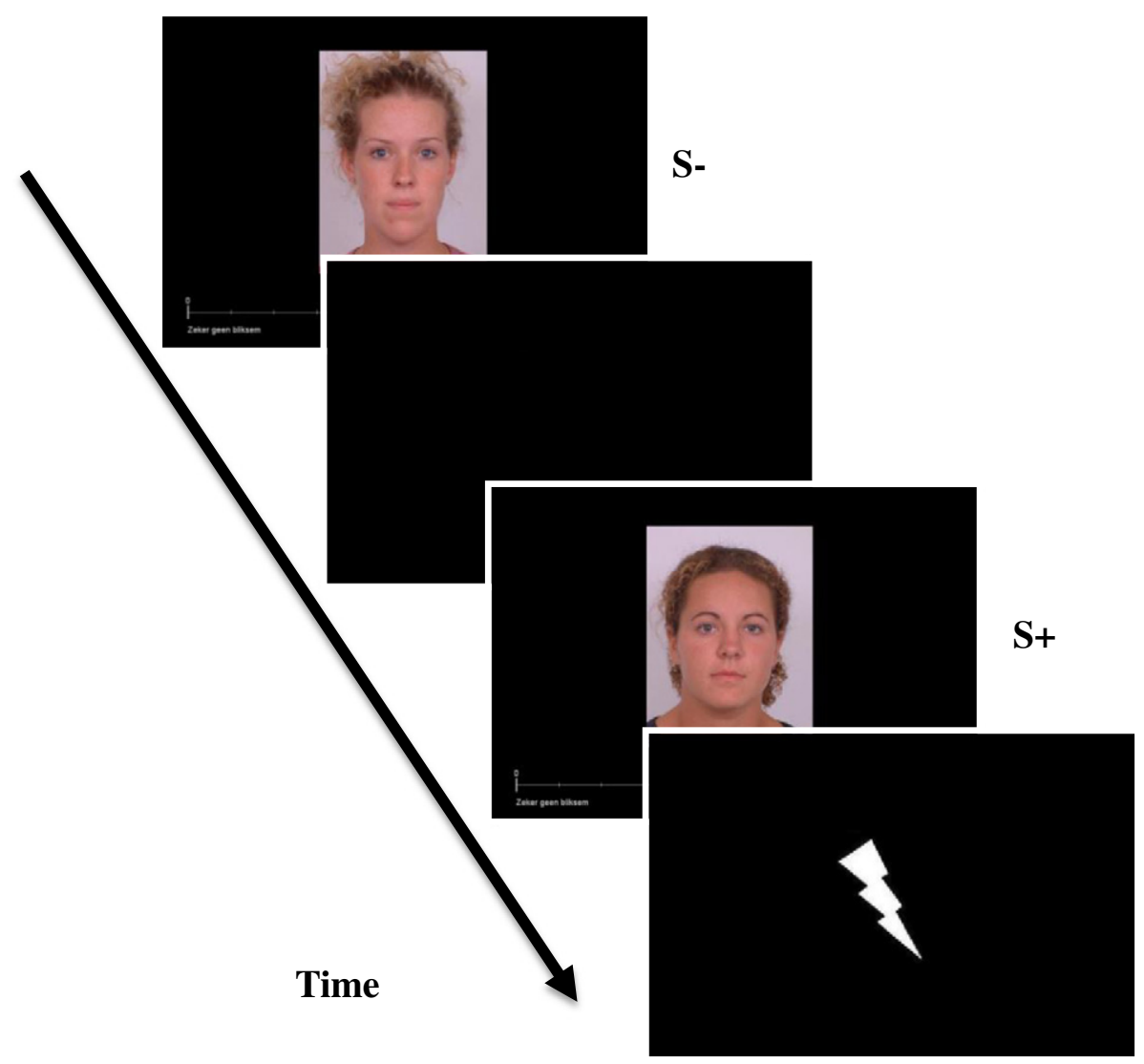

FIGURE 2 Example of the experimental trial sequence during the acquisition phase of the contingency learning task. 
were four types of trials, differing in the number of presented targets and distracters: Either one or three target squares presented alone (T1D0 and T3D0 trials, memory load of 1 or 3 items), or accompanied by two distractors (T1D2 and T3D2 trials). Task difficulty can be seen as a direct function of the number of targets and distracters presented. Each trial started with the presentation of an arrow cue for $500 \mathrm{~ms}$ indicating the half of the screen that had to be attended during the subsequent memory display, followed by a fixation cross presented for $1000 \mathrm{~ms}$ (Figure 3). After this, the sample array (T1D0, T3D0, T1D2, or T3D2) was shown for $150 \mathrm{~ms}$. After a retention interval of another $1000 \mathrm{~ms}$, a single test stimulus (colored square) was shown in the cued hemifield for a maximum of $5000 \mathrm{~ms}$, or was ended earlier at button response of the participant. The next trial started on average $2000 \mathrm{~ms}$ after button response.

\section{MEASURES}

\section{Index of Generalization}

During all $S_{+}, S_{-}$, and GS trials of the generalization task, participants were requested to indicate their expectancy of the outcome on an 11-point scale ranging from 0 to 10 (with 0 meaning "I am absolutely sure no lightning bolt will follow", and 10 meaning "I am absolutely sure a lightning bolt will follow"). The scale was presented at the bottom of the computer screen. Participants indicated their expectancy by moving a red dot across the scale using the left and right arrows, and confirmed their chosen expectancy rating by hitting ENTER. There was no time limit for this response.

Based on the outcome expectancy ratings during test of generalization, we calculated the following generalization index $(G I)$ : For each participant, the

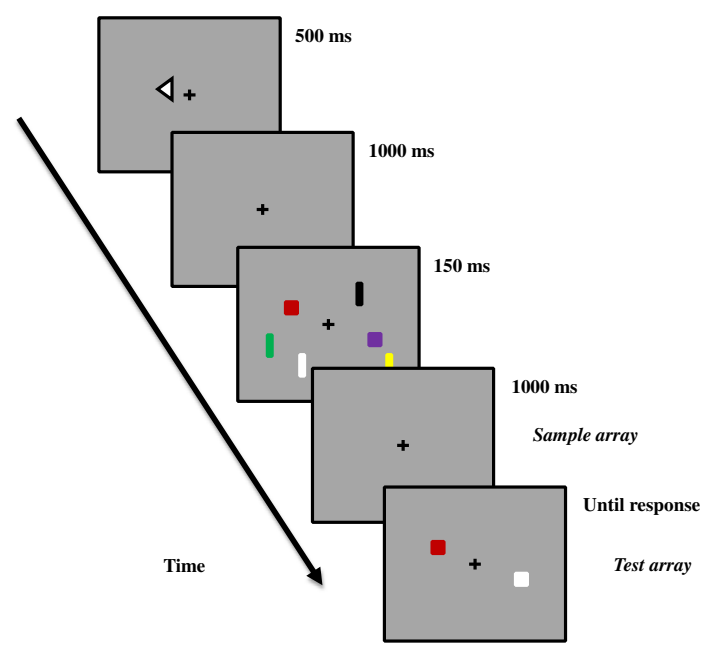

FIGURE 3 Example of a distracters-present trial (TID2) for the left hemifield during the visuospatial working memory task. sum of the expectancy ratings (or responses, $r$ ) of the six GS stimuli was calculated, normalized for individual $S$ + ratings, such that

$G I=\frac{\sum_{i=1}^{6} r_{i}}{r_{0}}$

where $i=0$ refers to the response for $\mathrm{S}+$ postacquisition and throughout generalization, and $i=$ $1, \ldots, 6$ to the responses for the six GSs. This index provides information about the total amount of generalization for each individual, with higher scores representing more generalization.

The numerator in the equation can be seen as a special case of area under the curve. This measure, which is frequently used in endocrinological research (e.g., to comprise information that is contained in repeated cortisol measurements over time) is calculated as the surface area under the curve that displays response values for each consecutive measurement (Fekedulegn et al., 2007; Pruesnner et al., 2003). Using the trapezoid formula, the surface area between every two adjacent data points is calculated with the measurements themselves (i.e., response strength) as height (on the y-axis), and the distance between the measurements as width (on the $\mathrm{x}$-axis). Whereas the time distance between measurements represents width in endocrinological research, the $\mathrm{x}$-axis contains the different generalization stimuli that differ in perceptual similarity in our case. To the extent that the physical distance (i.e., similarity) between the stimuli is held constant-which applies to most generalization studies-width can be omitted from the formula, leaving only the respective heights or response strengths to each of the GSs, which are to be summed. ${ }^{2}$ In the present study, physical distance between GSs was held constant by using morphs between the $\mathrm{S}+$ and the $\mathrm{S}$ - in six equal steps (i.e., steps of $14.29 \%$ from the $S+$ to the $S$-). Finally, this value is divided by the response to the $\mathrm{S}+$ to correct for individual differences in initial response strength. This step is facultative, but especially interesting when investigating generalization. For instance, if two individuals respond 10 and 5 to the $S$ + respectively, and 10 and 5 to all GSs respectively as well, these two response patterns differ considerably, but not with respect to generalization, which can be seen as being $100 \%$ for both individuals. Hence, dividing the summed response

\footnotetext{
${ }^{2}$ If the physical distances between stimuli are not constant, or if the perceived, psychological distance between stimuli is taken into account (Shepard, 1958), this can be easily captured by incorporating (differences in) distance between stimuli as width in the trapezoid formula.
} 
strengths for the GSs by the response strength to the $\mathrm{S}+$ results in the same GI value for both individuals.

Visual Working Memory Capacity and Filtering Cost

During the test phase of each trial of the VSWM task, participants were required to press a button with the left index finger when the test stimulus shown at this location had the same color as that in the previous sample array, or press another button with the right index finger when the color was different. The behavioral measure derived from his task was an estimate of memory capacity, $K$, which is calculated as

$K=S^{*}(\mathrm{H}-\mathrm{F}) /(1-\mathrm{F})$,

in which $\mathrm{H}$ is the hit rate, $\mathrm{F}$ is the false alarm rate and $S$ is the number of target items in the sample display (Linden et al., 2003; Pashler, 1988; Vogel et al., 2001). Higher values represent higher working memory capacity. We assessed working memory capacity in the absence (T1D0, T3D0) and presence (T1D2, T3D2) of distracter stimuli, with $K$ ranging between 0 and 1 for the low target load trials (T1D0, T1D2), and between 0 and 3 for the high target load trials (T3D0, T3D2). Following Spronk et al. (2012), we also calculated an index $C(K)$ for filtering cost on memory capacity by subtracting $K$ for trials with irrelevant distracter items from $K$ for trials without distracter items. We calculated this index for the high target load trials only, as these were most taxing on working memory. Formally, this is $C(K)=$ $K(\mathrm{~T} 3 \mathrm{D} 0)-K(\mathrm{~T} 3 \mathrm{D} 2)$. This index captures the efficiency to exclude irrelevant distracter items from access to memory, with higher values representing a higher cost (or loss in performance) on memory capacity due to the distracters.

\section{PROCEDURE}

Participants were seated in front of the computer at an eye-screen distance of approximately $57 \mathrm{~cm}$. First, the generalization task was administered, which consisted of a pre-acquisition phase, an acquisition phase, a post-acquisition test phase, and a generalization phase. Participants were informed that a number of pictures would appear on the screen, and that a drawing of a lightning bolt would sometimes follow these pictures. They were instructed that the goal of the task was to figure out which picture would be followed by a lightning bolt. During pre-acquisition, both the $S+$ and the $S$ - were presented three times, each without being followed by the outcome. In the acquisition phase, the $S+$ and the $\mathrm{S}$ - were presented 12 times each, with the $\mathrm{S}+$ being followed by the outcome nine times $175 \%$ reinforcement). In the post-acquisition test-phase, the $\mathrm{S}+$ and the S- were presented once without being followed by the outcome. During the generalization phase, three consecutive blocks of 10 trials were presented. Each block consisted of two $S+$ trials, two S- trials, and one trial for each of the six GSs. The outcome was presented once in each block, after one of the two $S+$ trials. This was done to prevent rapid extinction during the test of generalization. Throughout the experiment, trials were presented in semirandom order, with the restriction of no more than two consecutive trials of the same type. For analysis, responses to the three generalization test blocks were averaged to arrive at a single response measure for each type of generalization stimulus, and the average response to $S+$ post-acquisition and throughout generalization was used to correct for individual differences in response strength to $S+$.

In the subsequent VSWM task, participants were informed that the goal was to remember the location and colors of the squares in the cued hemifield, while ignoring any rectangles within the sample array. A total of 160 trials were presented. On half of the trials, the target squares were accompanied by distracter rectangles. At test, a change in color of the tested target square occurred in $50 \%$ of all test trials.

\section{Results}

\section{ACQUISITION}

Three participants ( 2 females, 1 male) did not show the expected increase in $S+$ outcome expectancy ratings during acquisition and were excluded from further analyses, because acquisition is a prerequisite for subsequent testing of generalization. The remaining 22 participants clearly acquired the discrimination between $\mathrm{S}_{+}$and $\mathrm{S}_{-}$, as evidenced by higher outcome expectancy ratings to $S+$ $($ Mean $=8.1, S E=0.5)$ compared with S(Mean $=0.5, S E=0.3)$ by the end of acquisition, relative to the last trial of pre-acquisition which served as a 'baseline' rating (Mean $\mathrm{S}+=1.7, \mathrm{SE}=$ 0.3 , Mean $\mathrm{S}-=2.4, S E=0.4)$. Figure 4 shows the

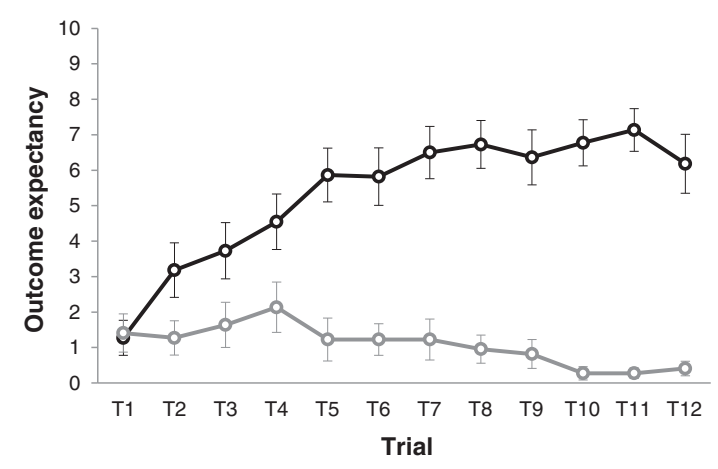

FIGURE 4 Mean outcome expectancy ratings for $\mathrm{S}+$ and $\mathrm{S}$ (+SEM) throughout the acquisition phase (trial I - trial 12) of the contingency learning task. 
$\mathrm{S}+$ and $\mathrm{S}$ - ratings during the acquisition phase. A repeated measures ANOVA with Stimulus $(\mathrm{S}+, \mathrm{S}-)$ and Time (pre-acquisition, post-acquisition) as within-subject variables revealed a main effect of Stimulus, $F(1,21)=88.3, M S E=3.0, p<0.001$, partial $\eta^{2}=0.81$, and of Time, $F(1,21)=44.2$, $M S E=2.6, p<0.001$, partial $\left.\eta^{2}=0.68\right)$, as well as a Stimulus $\times$ Time interaction effect $F(1,21)=$ 130.4, MSE $=2.9, p<0.001$, partial $\eta^{2}=0.86$. Paired comparisons of the $S+$ and $S$ - ratings showed significantly higher ratings at baseline for the $S$ relative to the $S_{+}, t(21)=1.7, p=0.018$, but $S_{+}$ ratings were markedly higher than $\mathrm{S}$ - ratings after acquisition $t(21)=-11.2, p<0.001$. Further, comparative analysis revealed a significant increase in outcome expectancy ratings for the $S+$ from trial 1 to trial 12 of acquisition, $F(11,231)=8.1$, $M S E=8.6, p<0.001$, partial $\eta^{2}=0.28$, and a significant decrease for the S-, $F(11,231)=2.3$, $M S E=2.8, p=0.011$, partial $\eta^{2}=0.1$.

\section{GENERALIZATION}

Figure 5 presents the mean outcome expectancy ratings $(+S E M)$ for the $S+$, the six GSs and the $S-$. Throughout the generalization phase, average responding $(+S E M)$ was $5.78(0.55)$ to $S+, 5.59$ $(0.73)$ to GS1, $4.09(0.73)$ to GS2, $3.18(0.80)$ to GS3, $1.88(0.50)$ to GS4, $1.20(0.50)$ to GS5, 0.41 $(0.26)$ to GS6, and $0.67(0.32)$ to S-. Outcome expectancies show a gradual decrease as the GSs become increasingly dissimilar to the $S+$, suggesting the presence of generalization. This was confirmed in a repeated measures ANOVA with Stimulus $\left(\mathrm{S}_{+}\right.$, GS1, GS2, GS3, GS4, GS5, GS6, S-) as withinsubject variable, which revealed a main effect of Stimulus $F(7,147)=42.9, M S E=2.3, p<0.001$, partial $\eta^{2}=0.67$. The calculation of our index of generalization resulted in a mean value of 2.6 $(S D=1.5)$ for the sample as a whole.

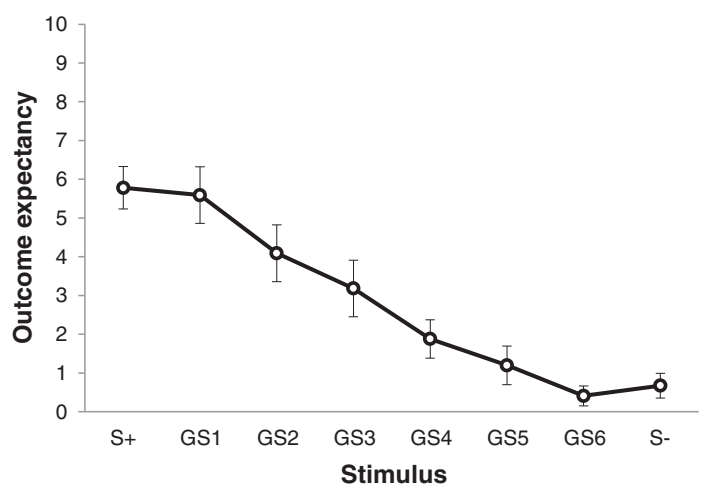

FIGURE 5 Mean outcome expectancy ratings for S+, S-, and the six GSs (+SEM) averaged over the three generalization test blocks of the contingency learning task.

\section{VISUAL WORKING MEMORY}

Data were trimmed by excluding $1 \%$ fastest and $1 \%$ slowest responses (Ratcliff, 1993). Mean memory capacity $(K)$ scores $(+$ SEM) for the four different trial types were: $K(\mathrm{~T} 1 \mathrm{D} 0)=0.77(0.05) ; K(\mathrm{~T} 1 \mathrm{D} 2)=$ $0.70(0.06) ; K(\mathrm{~T} 3 \mathrm{D} 0)=2.07(0.15) ; K(\mathrm{~T} 3 \mathrm{D} 2)=$ 1.31 (0.17). A repeated measures ANOVA with memory capacity as the dependent variable, and Target Load (T1, T3) and Distracters (D0, D2) as within-subject factors revealed a main effect of Target Load, $F(1,21)=79.8, M S E=0.25$, $p<0.001$, partial $\eta^{2}=0.79$, a main effect of Distracters, $F(1,21)=31.9, M S E=0.12$, $p<0.001$, partial $\eta^{2}=0.60$, and a Target Load $\times$ Distracters interaction effect, $F(1,21)=20.7$, $M S E=0.12, p<0.001$, partial $\eta^{2}=0.50$. Subsequent analyses showed that the presence of distracters impaired memory capacity at low (T1D0 vs T1D2: $F[1,21]=4.9, M S E=0.01, p=0.038$, partial $\left.\eta^{2}=0.19\right)$ and at high memory load (T3D0 vs T3D2: $F[1,21]=27.4, M S E=0.23, p<0.001$, partial $\left.\eta^{2}=0.57\right)$.

\section{ASSOCIATION BETWEEN GENERALIZATION} AND WORKING MEMORY

Here, we will limit our focus to the high target load trials for memory capacity $K, K(\mathrm{~T} 3 \mathrm{D} 0)$, as well as for filtering cost $C(K), K(\mathrm{~T} 3 \mathrm{D} 0)-K(\mathrm{~T} 3 \mathrm{D} 2)$, as these trials are most taxing on working memory. First, to investigate whether generalization was associated with working memory capacity, a correlation analysis between our generalization index GI and working memory capacity at high memory load, $K(\mathrm{~T} 3 \mathrm{D} 0)$, revealed no significant association $(p=0.50)$.

Subsequently, we analyzed generalization as a function of individual differences in the efficiency at filtering out irrelevant items from access to working memory (Spronk et al., 2012). Interestingly, we found a significant correlation between $C(K)$ and our index of generalization, $r=0.53, p=0.012$, such that increased generalization was associated with a higher cost on working memory capacity due to filtering of irrelevant distracter items. It is noteworthy that the correlation between filtering cost and the not-normalized GI (i.e., without correction for responding to $\mathrm{S}_{+}$) gave a similar result, $r=0.44, p=0.043$.

Finally, we investigated whether working memory filtering cost was also associated with discrimination learning during acquisition. Accurate discrimination learning also requires the comparison of similar events $(\mathrm{S}+$ and $\mathrm{S}$ - presentations), and the correct identification of the predictive relationships between the $\mathrm{S}_{+}$, the $\mathrm{S}_{-}$, and the outcome, and could therefore depend on working memory as 
well. To investigate this possibility, we calculated an index for acquisition $(A I)$ as the difference between the first and last acquisition trials, $A I=C S+1_{-}$ $C S+{ }_{12}$, and an index for discrimination $(D I), D I=$ $\left[C S+{ }_{12}-C S-{ }_{12}\right]-\left[C S+{ }_{1}-C S-{ }_{1}\right]$. We then correlated the filter cost index $C(K)$ with $A I$ and with $D I$. Neither correlation coefficients were significant $\left(p_{\mathrm{AI}}=0.49, p_{\mathrm{DI}}=0.52\right)$, which indicates that filtering cost of working memory did not affect discrimination learning during acquisition.

\section{Discussion}

In the present study, we investigated the relationship between working memory capacity and generalization. We found that individuals who were less efficient at filtering out irrelevant information from access to memory showed higher levels of generalization. Further, we presented an index of generalization that captures individual differences in the extent of generalization in a single continuous measure.

Importantly, generalization was not associated with individual differences in working memory capacity as such. Rather, it was associated with the loss in working memory capacity caused by presenting irrelevant information. This filtering efficiency may be central to generalization on the basis of prior experience. To the extent that generalization is based on a comparison between the current situation and previous learning experiences, it is crucial to take into account relevant information while ignoring irrelevant information. If a robbery victim is not able to ignore stimuli in new situations that are similar to the traumatic event but that possess no predictive information on the likelihood of a novel victimization (e.g., the color of the jacket the assailant was wearing, or the fact that it was raining at the time of the incident), generalization may become too excessive. In posttraumatic stress disorder, for instance, reexperiencing of the trauma is often triggered by these neutral, seemingly irrelevant stimuli. Based on the current findings, individual differences in the ability to keep these irrelevant stimuli from access to working memory may be associated with elevated generalization. As both working memory impairments (for a recent review, see Snyder, Miyake, \& Hankin, 2015) and elevated generalization (Lissek et al., 2010; Lissek et al., 2014; Lissek \& Grillon, 2012) are known to be associated with different forms of psychopathology, future research should focus on the interplay between these factors in the development of psychological complaints and disorders.

With respect to anxiety disorders specifically, our findings may suggest that elevated levels of generalization previously shown in individuals with an anxiety disorder may be due to a limited ability to filter out information from working memory. In this respect, research has revealed attentional biases towards threat in anxiety disorders, such as facilitated detection of threat signals or difficulty in disengaging attention from threat signals (Cisler \& Koster, 2010). To the extent that these attentional biases occupy working memory, less resources may be available for accurate discrimination between dangerous and safe stimuli or situations, resulting in higher levels of generalization. For instance, Lissek and colleagues (2010) showed that individuals suffering from panic disorder showed higher levels of fear generalization, relative to healthy individuals, to stimuli that were perceptually similar to a stimulus that was previously paired with an aversive outcome (i.c., electrocutaneous stimuli). A possible explanation may be that biased attention towards the potential occurrence of an aversive stimulus led to a loss in working memory capacity, which in turn impaired discrimination between the danger signal and perceptually similar but innocuous stimuli. Note that, although the aversive outcome does not represent irrelevant information, it can function as a distracter stimulus occupying cognitive resources that are necessary for processing relevant information that allows to discriminate between danger and safety signals. Interestingly, previous research has shown that the presentation of fear-related distracter stimuli impairs working memory in a visual working memory task (Dolcos \& McCarthy, 2006). To the extent that individuals suffering from an anxiety disorder are more easily distracted by emotional threat-related information, working memory may be impaired, potentially resulting in deficient discrimination and elevated generalization. Of course, this hypothesis remains to be tested, and caution is warranted when extending our findings to anxiety disorders, as we did not assess anxiety symptomatology or test clinically anxious individuals in this study. Future research investigating the relation between generalization and working memory in individuals suffering from an anxiety disorder is warranted, and could assess to what extent threat-related attentional biases impair working memory capacity.

Another area for future research concerns the learning paradigm that is used. In the present study, we used a contingency-learning procedure with neutral stimuli and a relatively neutral outcome. Although the main purpose of the present study was to investigate working memory in relation to generalization as a fundamental behavioral phenomenon, future studies could use a conditioning procedure with a biologically aversive outcome (such as an electric shock) to assess whether working 
memory is differently related to generalization in these learning procedures.

We found no relation between working memory capacity or filtering efficiency and acquisition, which also required the comparison of similar events $(S+$ and $S$ - presentations), and the correct identification of the predictive relationships between the $S_{+}$, the $S_{-}$, and the outcome. However, it is very likely that individual differences in working memory had no effect on acquisition because this phase was much easier and, hence, demanded less working memory capacity relative to generalization. The generalization task was more difficult for at least two reasons: First, there was higher perceptual similarity between the GSs than between the $\mathrm{S}+$ and the S-. Second, as the GSs contained features of both the $\mathrm{S}+$ and the S-, these stimuli were inherently ambiguous.

Whereas this study investigated the relation between working memory and generalization from an individual differences perspective, future studies could manipulate working memory capacity, for instance by installing a secondary task load. This would allow drawing more firm conclusions on working memory as a cognitive process causally involved in generalization. Further, another interesting pathway for future research with potential clinical implications is to train working memory capacity, and investigate whether improvements in working memory are associated with decreases in generalization.

Further, we presented an index of generalization that captures responding to different generalization stimuli in a single continuous measure. Another generalization index has recently been proposed by Kaczkurkin and Lissek (2013). This index is said to capture the amount of deviation from a linear generalization gradient. In a number of studies, Lissek and colleagues evidenced that individuals suffering from clinical anxiety showed a linear decrease in generalization, whereas healthy individuals showed a steeper, more quadratic decrease in generalization (Lissek et al., 2010; Lissek et al., 2014). Their index is calculated by subtracting the mean response over all GSs from the mean response over the $S+$ and the S-. In the case of four GSs for instance, the formula is: Mean (CS + and CS-) - Mean (GS1, GS2, GS3, GS4). However, Kaczkurkin and Lissek's cannot capture deviation from linearity under all circumstances. Suppose that, if four GSs are presented, responding is scored 10 to $S+, 8$ to GS1, 6 to GS2, 4 to GS3, 2 to GS4, and 0 to S-. In this example, generalization is perfectly linear and the resulting value of the generalization index will be zero. Suppose now, that responding to $S_{+}$, the four GSs, and $S_{-}$is, $10,10,10$, $0,0,0$ respectively. In this case, the resulting generalization value will be zero as well, although a considerable deviation from linearity has occurred. In that respect, the interpretation of the values of this index is not straightforward, as it is not clear, for instance, what a value of zero signifies. Finally, this index is somewhat limited in its applicability to generalization studies, because it can only be used for paradigms where both a $S$ + and a $S$ - are presented, which is certainly not always the case (e.g., single stimulus training; Honig \& Urcuioli, 1981).

In contrast, the index we presented here has the advantage of being applicable to all generalization procedures on the one hand, and has a more straightforward interpretation on the other hand, with higher values indicating more generalization. In summary, our index captures the total amount (or 'mass' for lack of a better term) of responding to the $\mathrm{S}+$ that has generalized to the GSs. It does not, however, provide information about the exact shape or slope of the gradient. If one were interested in individual differences in the shape or slope of the gradient, only more recently, more complex statistical analyzing strategies are being applied to the field of generalization research that can provide information on the shape of generalization by estimating subject-specific slopes of the gradient (i.e., multilevel analysis; Gazendam et al., 2014; Vanbrabant et al., 2015).

In conclusion, in this study we found higher levels of generalization in individuals who were less efficient at filtering out irrelevant information from access to working memory. Further, we provided an index that captures the amount of generalization in a single continuous measure. Thus, by providing new insights in the cognitive factors associated with generalization on the one hand, and by offering a new tool to investigate generalization on the other hand, we hope to inspire new research and new research questions on the topic of generalization.

\section{Conflict of Interest Statement}

The authors declare that there are no conflicts of interest.

\section{References}

Baddeley, A. (2012). Working memory: theories, models, and controversies. Annual Review of Psychology, 63, 1-29. http://dx.doi.org/10.1146/annurev-psych-120710-100422

Cisler, J. M., \& Koster, E. H. W. (2010). Mechanisms of attentional biases towards threat in anxiety disorders: An integrative review. Clinical Psychology Review, 30, 203-216. http://dx.doi.org/10.1016/j.cpr.2009.11.003

Cowan, N. (2001). The magical number 4 in short-term memory: A reconsideration of mental storage capacity. Behavioral and Brain Sciences, 24, 87-114. http://dx.doi.org/ 10.1017/S0140525X01003922

DeBruine, L. M. (2005). Trustworthy but not lust-worthy: Context-specific effects of facial resemblance. Proceedings of the Royal Society of London B, 272, 919-922. http://dx.doi.org/10.1098/rspb.2004.3003 
De Houwer, J., \& Beckers, T. (2002). A review of recent developments in human contingency learning research. Quarterly Journal of Experimental Psychology. B, 55, 289-310. http://dx.doi.org/10.1080/02724990244000034

De Houwer, J., \& Beckers, T. (2003). Secondary task difficulty modulates forward blocking in human contingency learning. Quarterly Journal of Experimental Psychology. B, Comparative and Physiological Psychology, 56, 345-357. http://dx.doi.org/10.1080/ 02724990244000296

Dolcos, F., \& McCarthy, G. (2006). Brain systems mediating cognitive interference by emotional distraction. The Journal of Neuroscience, 26, 2072-2079. http://dx.doi.org/ 10.1523/JNEUROSCI.5042-05.2006

Fekedulegn, D. B., Andrew, M. E., Burchfiel, C. M., Violanti, J. M., Hartley, T. A., Charles, L. E., \& Miller, D. B. (2007). Area under the curve and other summary indicators of repeated waking cortisol measurements. Psychosomatic Medicine, 69, 651-659. http://dx.doi.org/10.1097/PSY.0b013e31814c405c

Gazendam, F. J., Kamphuis, J. H., Eigenhuis, A., Huizenga, H. M. H., Soeter, M., Bos, M. G. N., ... Kindt, M. (2014). Personality predicts individual variation in fear learning: A multilevel growth modeling approach. Clinical Psychological Science, 3, 175-188. http://dx.doi.org/10.1177/ 2167702614535914

Ghirlanda, S., \& Enquist, M. (2003). A century of generalization. Animal Behaviour, 66, 15-36. http://dx.doi.org/10.1006/ anbe.2003.2174

Honig, W. K., \& Urcuioli, P. J. (1981). The legacy of Guttman and Kalish (1956): 25 years of research on stimulus generalization. Journal of Experimental Analysis of Behavior, 3, 405-445. http://dx.doi.org/10.1901/jeab.1981.36-405

Kaczkurkin, A. N., \& Lissek, S. (2013). Generalization of conditioned fear and obsessive-compulsive traits. Journal of Psychology and Psychotherapy, S7, 003. http://dx.doi.org/ 10.4172/2161-0487.S7-003

Kane, M. J., \& Engle, R. W. (2003). Working-memory capacity and the control of attention: The contributions of goal neglect, response competition, and task set to Stroop interference. Journal of Experimental Psychology: General, 132, 47-70. http://dx.doi.org/10.1037/ 0096-3445.132.1.47

Lenaert, B., Claes, S., Raes, F., Boddez, Y., Joos, E., Vervliet, B., et al. (2012). Generalization of conditioned responding: Effects of autobiographical memory specificity. Journal of Behavior Therapy and Experimental Psychiatry, 43, S60-S66. http://dx.doi.org/10.1016/j.jbtep.2010.12.010

Linden, D. E. J., Bittner, R. A., Muckli, L., Waltz, J. A., Kriegeskorte, N., Goebel, R., \& Munk, M. H. J. (2003). Cortical capacity constraints for visual working memory: Dissociation of fMRI load effects in a fronto-parietal network. NeuroImage, 20, 1518-1530. http: //dx.doi.org/10.1016/j.neuroimage.2003.07.021.

Lissek, S., \& Grillon, C. (2012). Learning models of PTSD. In Beck, J. G., Sloan, D. M., (Eds.), The Oxford Handbook of Traumatic Stress Disorders. New York: Oxford University Press.

Lissek, S., Kaczkurkin, A. N., Rabin, S., Geraci, M., Pine, D. S., \& Grillon, C. (2014). Generalized anxiety disorder is associated with overgeneralization of classically conditioned fear. Biological Psychiatry, 75, 909-915. http://dx.doi.org/ 10.1016/j.biopsych.2013.07.025

Lissek, S., Rabin, S., Heller, R. E., Lukenbaugh, D., Geraci, M., Pine, D. S., \& Grillon, C. (2010). Overgeneralization of conditioned fear as a pathogenic marker of panic disorder. American Journal of Psychiatry, 167, 47-55. http://dx.doi.org/ 10.1176/appi.ajp.2009.09030410
Livesey, E. J., \& McLaren, I. P. L. (2009). Discrimination and generalization along a simple dimension: Peak shift and rulegoverned responding. Journal of Experimental Psychology: Animal Behavior Processes, 35, 554-565. http://dx.doi.org/ 10.1037/a0015524

Meulders, A., Jans, A., \& Vlaeyen, J. W. S. (2015). Differences in pain-related fear acquisition and generalization: an experimental study comparing patients with fibromyalgia and healthy controls. PAIN, 156, 108-122. http://dx.doi.org/ 10.1016/j.pain.0000000000000016

Mitchell, C. J., De Houwer, J., \& Lovibond, P. F. (2009). The propositional nature of human associative learning. Behavioral and Brain Sciences, 32, 183-246. http://dx.doi.org/ 10.1017/S0140525X09000855

Pashler, H. (1988). Familiarity and visual change detection. Perception \& Psychophysics, 44, 369-378. http: //dx.doi.org/10.3758/BF03210419.

Pruessner, J. C., Kirschbaum, C., Meinlschmid, G., \& Hellhammer, D. H. (2003). Two formulas for computation of the area under the curve represent measures of total hormone concentration versus time-dependent change. Psychoneuroendocrinology, 28, 916-931. http://dx.doi.org/ 10.1016/S0306-4530(02)00108-7

Raes, A. K., De Raedt, R., Verschuere, B., \& De Houwer, J. (2009). Failure to loose fear: The impact of cognitive load and trait anxiety on extinction. Behaviour Research and Therapy, 47, 1096-1101. http://dx.doi.org/ 10.1016/j.brat.2009.08.002

Ratcliff, R. (1993). Methods for dealing with reaction time outliers. Psychological Bulletin, 114, 510-532. http://dx.doi.org/ 10.1037/0033-2909.114.3.510

Shepard, R. N. (1958). Stimulus and response generalization: Deduction of the generalization gradient from a trace model. Psychological Review, 65, 242-256. http://dx.doi.org/ 10.1037/h0043083

Snyder, H. R., Miyake, A., \& Hankin, B. L. (2015). Advancing understanding of executive function impairments and psychopathology: Bridging the gap between clinical and cognitive approaches. Frontiers in Psychology, 6, 328. http://dx.doi.org/ 10.3389/fpsyg.2015.00328

Spronk, M., Vogel, E. K., \& Jonkman, L. M. (2012). Electrophysiological evidence for immature processing capacity and filtering in visuospatial working memory in adolescents. PloS One, 7, e42262. http://dx.doi.org/10.1371/ journal.pone.0042262

Spruyt, A., Clarysse, J., Vansteenwegen, D., Baeyens, F., \& Hermans, D. (2010). Affect 4.0: A free software package for implementing psychological and psychophysiological experiments. Experimental Psychology, 57, 36-45. http://dx.doi.org/ 10.1027/1618-3169/a000005

Taylor, J. M. G., \& Yu, M. (2002). Bias and efficiency loss due to categorizing an explanatory variable. Journal of Multivariate Analysis, 83, 248-263. http://dx.doi.org/10.1006/ jmva.2001.2045

Vanbrabant, K., Boddez, Y., Verduyn, P., Mestdagh, M., Hermans, D., \& Raes, F. (2015). A new approach for modeling generalization gradients: A case for Hierarchical Models. Frontiers in Psychology, 6. http: //dx.doi.org/10.3389/fpsyg.2015.00652.

Vogel, E. K., \& Machizawa, M. G. (2004). Neural activity predicts individual differences in visual working memory capacity. Nature, 428, 1997-2000. http://dx.doi.org/ 10.1038/nature02447

Vogel, E. K., McCollough, A. W., \& Machizawa, M. G. (2005). Neural measures reveal individual differences in controlling access to working memory. Nature, 438, 500-503. http://dx.doi.org/10.1038/nature04171 
Vogel, E. K., Woodman, G. F., \& Luck, S. J. (2001). Storage of features, conjunctions, and objects in visual working memory. Journal of Experimental Psychology: Human Perception and Performance, 27, 92-114. http://dx.doi.org/10.1037/ 0096-1523.27.1.92

Wills, A. J., Graham, S., Koh, Z., McLaren, I. P. L., \& Rolland, M. D. (2011). Effects of concurrent load on feature- and rulebased generalization in human contingency learning. Journal of Experimental Psychology. Animal Behavior Processes, 37, 308-316. http://dx.doi.org/10.1037/a0023120
Zanto, T. P., \& Gazzaley, A. (2009). Neural suppression of irrelevant information underlies optimal working memory performance. Journal of Neuroscience, 29, 3059-3066. http://dx.doi.org/10.1523/JNEUROSCI.4621-08.2009

Received: July 8, 2015

Accepted: October 8, 2015

Available online 20 October 2015 